\title{
USING RECENT ADVANCES IN 2D SEISMIC TECHNOLOGY AND SURFACE GEOCHEMISTRY TO ECONOMICALLY REDEVELOP A SHALLOW SHELF CARBONATE RESERVOIR: VERNON FIELD, ISABELLA COUNTY, MI.
}

TYPE OF REPORT: QUARTERLY

REPORTING PERIOD START DATE: JULY 1, 2001

REPORTING PERIOD END DATE: SEPTEMBER 30, 2001

PRINCIPAL AUTHORS:

JAMES R. WOOD, T. J. BORNHORST, S. D. CHITTICK - MICHIGAN TECHNOLOGICAL UNIVERSITY, HOUGHTON, MI

WILLIAM B. HARRISON, WESTERN MICHIGAN UNIVERSITY, KALAMAZOO, MI

W. QUINLAN, CRONUS EXPLORATION COMPANY LLC, TRAVERSE CITY, MI

DATE REPORT WAS ISSUED: OCTOBER 31, 2001

DOE AWARD NUMBER: DE-AC26-00BC15122

NAME AND ADDRESS OF SUBMITTING ORGANIZATION:

MICHIGAN TECHNOLOGICAL UNIVERSITY

1400 TOWNSEND DRIVE

HOUGHTON, MI. 49931 
Two major accomplishments resulted from Phase I. One is the success of the surface geochemistry program, which collected over 800 samples from the site of the $1^{\text {st }}$ demonstration well in Vernon Field and has pretty well provided us with the tools to delineate favorable ground from unfavorable. The second is the recent detailed mapping of the Central Michigan Basin that for the first time revealed the presence of at least two major faults that control the location of many of the reservoirs in the Michigan Basin. These faults were located from structure maps obtained by contouring the surface of the Dundee Formation using top picks from 9861 wells in 14 counties. Faults were inferred where the contour lines were most dense ("stacked").

- Results - The main results from this period are delineation of two major faults in the Central Michigan Basin. They extend $100-150$ miles in a Northwest - Southeast direction and have a maximum vertical relief of $500-600$ feet. The general picture is a structural providence of several broad elongate plateaus bounded by steep faultcontrolled escarpments that drop abruptly over 500 feet to form deep-basin valley floors.

- How Results will be Used and Why - The new structural picture of the Michigan Basin will be used to prepare a new exploration model for the basin based on a strategy of conducting surface geochemistry surveys over areas that appear to be gaps in the current exploration coverage.

- Remarkable Findings/Unexpected Results -The results of this recent structural analysis are both remarkable and unexpected and will have a major impact on the understanding of the internal structure of the Central Michigan Basin as well as laying a foundation for a new exploration model.

- Potential Applications -One of the more obvious potential applications of our new structural model is to develop an exploration strategy for the Central Michigan Basin based on the knowledge of what controls the locutions of fields and where gaps exist.

- Did data support project as expected or not? - These new data/findings strongly support the project since they could lead to new ways to look for hydrocarbons in Michigan and perhaps in similar intercratonic basins elsewhere.

- What remains to be done? - A number of tasks remain to be done. The most immediate include constructing accurate structural cross-sections that include key horizons, relating the structural data to the gravity data and constructing a model that relates the sedimentary structures to the paleo-rift environment.

- Should something else have been done? - If we had known going into this project that re-working the existing formation tops data would yield such a detailed picture of the Central Basin structure, we might have focussed on that earlier in the project.

- What lesson was learned? Several lessons were learned, possibly foremost being that the old drilling records are still a valuable source of data.

- Future plans - We intend to keep pursuing this new direction, refining and filling in the basin model as well as using it to suggest areas that are possible targets for surface geochemistry surveys. 


\section{DISCLAIMER}

This report was prepared as an account of work sponsored by an agency of the United States Government. Neither the United States Government nor any agency thereof, nor any of their employees, makes any warranty, express or implied, or assumes any legal liability or responsibility for the accuracy, completeness, or usefulness of any information, apparatus, product or process disclosed, or represents that its use would not infringe on any privately owned rights. Reference herein to any specific commercial product, process, or service by trade name, trademark, manufacturer, or otherwise, does not necessarily constitute or imply its endorsement, recommendation or favoring by the United States Government nor any agency thereof. The views and opinions of authors expressed herein do not necessarily state or reflect those of the United States Government. 


\section{LIST OF GRAPHICAL MATERIALS}

Figure 1. Index map showing locations of all wells used in delineating major basin faults in Central Michigan.

Figure 2. Structure contour map on top of the Dundee Formation in the Central Michigan Basin showing locations of major faults.

Figure 3. Location map for microbial samples in Central Michigan Basin. 


\section{EXECUTIVE SUMMARY}

The major result for this past period was the mapping of two hitherto unknown /unmapped faults in the Central Michigan Basin. These faults were discovered through detailed mapping over a large -scale of formation tops data collected during the project. The two major faults identified appear to border deep basin "holes" in the Dundee Formation top surface and also appear to control the distribution of some major hydrocarbon deposits. A number of the larger fields in the Dundee are located in small closures on the upthrown sides of these faults. Work is in progress to further map these faults, including looking at other horizons and constructing cross-sections.

The geochemical sampling team collected additional samples at Vernon Field and nearby, bringing the total number of sample collected to over 1500 along 8 traverses. Most of the locations were analyzed using the GMS microbial techniques and will be analyzed for soil iodine and soil gas. As previously reported studies were begun collecting and analyzing hydrocarbon gases $(\mathrm{C} 1-\mathrm{C} 8)$ directly at MTU. We have set up a gas chromatograph and have begun running samples. Eventually we hope to run all samples for soil gas and sorbed soil gases.

Possible sites for two further demonstration wells are being evaluated, one an extension to the Vernon Field and a second in the Dundee Formation to the Northeast of Vernon. Surface geochemistry is still being run over these sites and the results will be discussed this winter at the annual meeting

Two additional parties, an independent consultant and a small company, have asked us to run geochemical samples for them over several of their prospects. We take this as a positive sign that people are taking a second look at the usefulness of surface geochemistry surveys and we will probably oblige them in the not too distant future. Both prospects are in shallow shelf carbonates. In addition, a student supported on the project has finished collecting data over a pinnacle reef complex in Manistee County, Michigan and has obtained very promising results. It appears that he has succeeded in imaging a reef and plans are moving ahead to drill the prospect.

A $3^{\text {rd }}$ annual meeting for the Class Revisit work group is tentatively scheduled for the week of March 1-7 in Tampa, Fl. 


\section{TABLE OF CONTENTS}

USING RECENT ADVANCES IN 2D SEISMIC TECHNOLOGY AND SURFACE GEOCHEMISTRY TO ECONOMICALLY REDEVELOP A SHALLOW SHELF CARBONATE RESERVOIR: VERNON FIELD, ISABELLA COUNTY, MI. 1

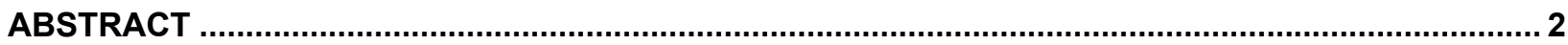

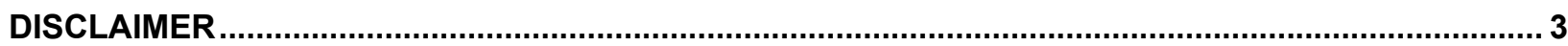

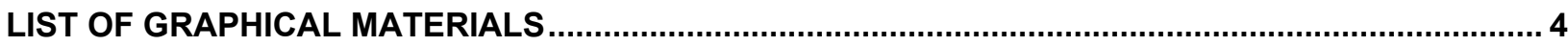

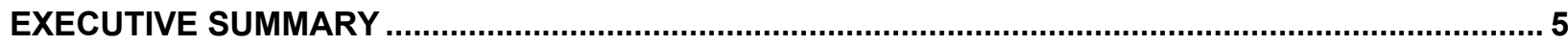

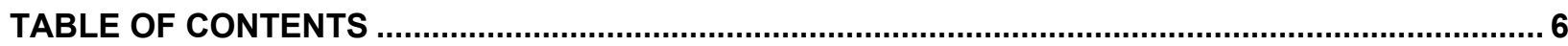

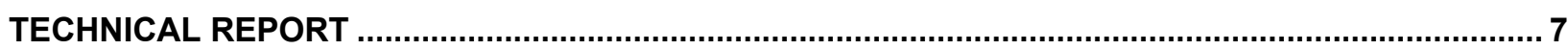

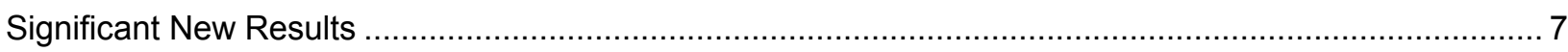

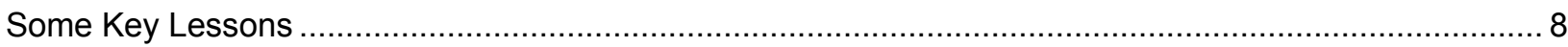

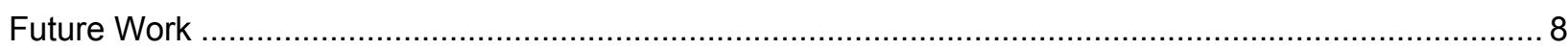

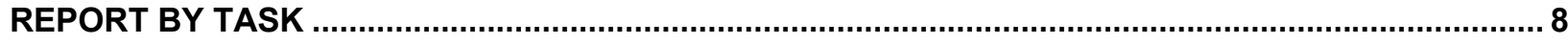

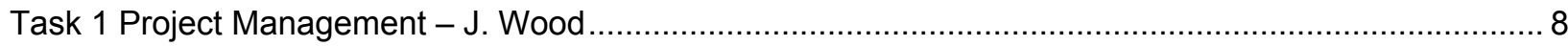

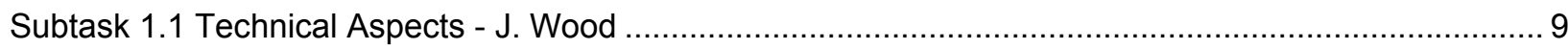

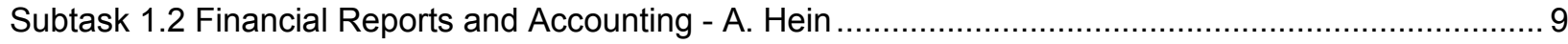

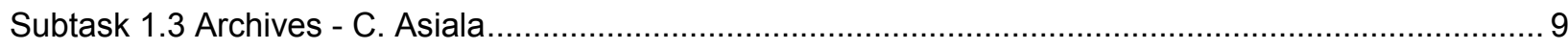

Task 2 Reservoir Characterization - W. Harrison .................................................................... 10

Subtask 2.1 Surface Geochemistry - T. Bornhorst ................................................................. 10

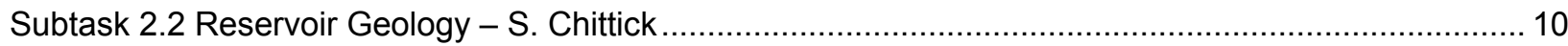

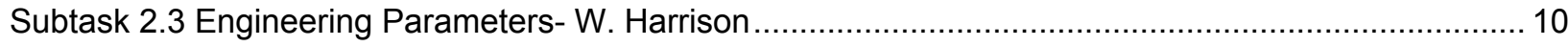

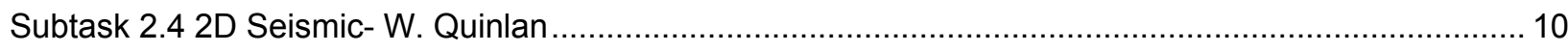

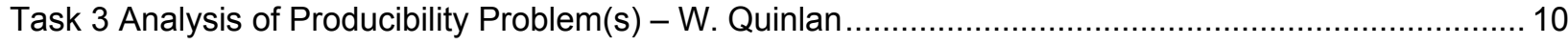

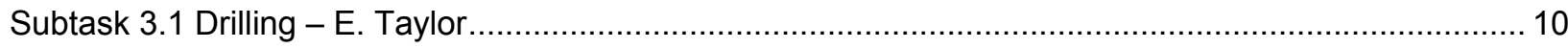

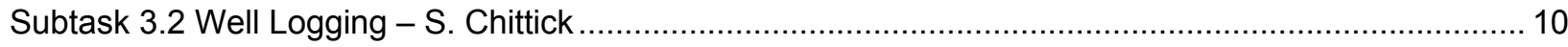

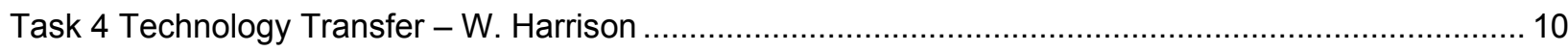

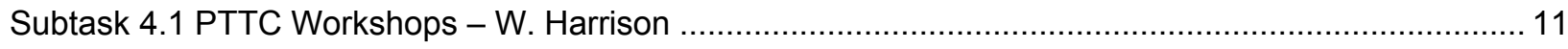

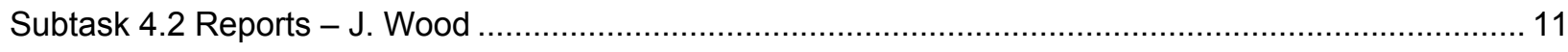

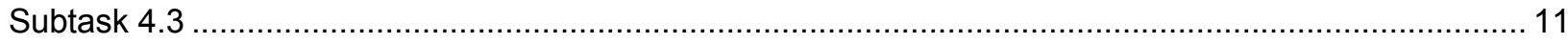

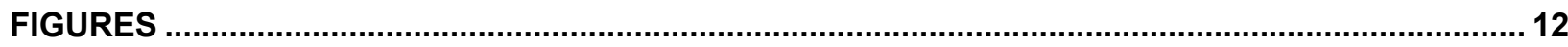




\section{TECHNICAL REPORT}

The main goal of Budget Phase II is to develop an exploration strategy based on results of the previous Phase. Specifically we need to identify sites for new demonstration wells using our new structure model for the Central Michigan Basin described. We plan to do this in conjunction with a revised surface geochemistry program.

This project enters Budget Phase II with two major accomplishments from Phase I. One is the success of the surface geochemistry program, which collected over 800 samples from the site of the $1^{\text {st }}$ demonstration well in Vernon Field and has pretty well provided us with the tools to delineate favorable ground from unfavorable. The second is the recent detailed mapping of the Central Michigan Basin that for the first time revealed the present of at least two major faults that control the location of many of the reservoirs in the Michigan Basin. These faults were located from structure maps obtained by contouring the surface of the Dundee Formation using top picks from 9861 wells in 14 counties (Figure 1). Faults were inferred where the contour lines were most dense ("stacked").

\section{Significant New Results}

The main results from this period are delineation of two major faults in the Central Michigan Basin (Figure 2). More ancillary faults undoubtedly remain to be mapped. However, the faults mapped to date are impressive in their scale and appear to be major controls on the tectonics and oil distribution in the Central Basin. They extend $100-150$ miles in a Northwest Southeast direction and have a maximum vertical relief of $500-600$ feet. The general picture is a structural providence of several broad elongate plateaus bounded by steep faultcontrolled escarpments that drop abruptly over 500 feet to form deep-basin valley floors. The valley floors are particularly pronounced in two areas where they form two deep basins separated by a single narrow plateau. The steep ridges are consistent with normal faults and known reservoirs lie close to the faults on the upthrown sides. It has long been known that oil fields in the Michigan Basin define persistent linear trends in the Central Basin and undoubtedly many wells were spotted based on extrapolation of these trends.

The new structural picture of the Michigan Basin will be used to prepare a new exploration model for the basin based on a strategy of conducting surface geochemistry surveys over areas that appear to be gaps in the current exploration coverage. The new model provides detailed exploration-scale prospect maps in which existing fields can be used as analogs for unexplored areas.

The results of this recent structural analysis are both remarkable and unexpected and will have a major impact on the understanding of the internal structure of the Central Michigan Basin as well as laying a foundation for a new exploration model. These results were unexpected and came as a result of work on a complementary DOE project aimed at looking for evidence of fractures and faults in the Michigan Basin in general. However, these results clearly fit into the present exploration/demonstration format of the Class Revisit Program and will be exploited in this program

One of the more obvious potential applications of our new structural model is to develop an exploration strategy for the Central Michigan Basin based on the knowledge of what controls the locutions of fields and where gaps exist. For example, it is clear that many fields lie close to the major faults on the upthrown side. It is also clear that there are a number of regions along these faults where there is poor well control and the contours don't look "right", that is they are too regular compared to nearby areas that have been more extensively drilled. These new data/findings strongly support the project since they could lead to new ways to 
look for hydrocarbons in Michigan and perhaps in similar intercratonic basins elsewhere.

\section{Some Key Lessons}

If we had known going into this project that re-working the existing formation tops data would yield such a detailed picture of the Central Basin structure, we might have focussed on that earlier in the project. However, what made the difference was finally looking at the data on the right scale (i.e. looking at detailed structure contour maps over several counties instead of single fields). It also helped to get the contour intervals set just right, too few and the structure does not show up, too many and the structure is obliterated. In this case it was basically persistence in re-working the data trying different approaches that finally paid off. It also helped immensely that software development had progressed to the point that we were able to redo maps many times, changing and adjusting parameters, which resulted in the discovery.

Several lessons were learned, possibly foremost being that the old drilling records are still a valuable source of data. It does pay to keep looking at the data as new conceptual models and new technologies become available. We feel that we are essential now just at the beginning of revising the structure and exploration model for the Michigan Basin, and by analogy, perhaps for analogous basins as well. Combined with the progress we have made learning about and using surface geochemistry, we are optimistic that we will emerge with a new paradigm for interior basin exploration.

\section{Future Work}

A number of tasks remain to be done. The most immediate include constructing accurate structural cross-sections that include key horizons, relating the structural data tot the gravity data and constructing a model that relates the sedimentary structures to the paleo-rift environment.

We intend to keep pursuing this new direction, refining and filling in the basin model as well as using it to suggest areas that should be targets for surface geochemical surveys and eventually drilling prospects. In that vein, we have several opportunities to run geochemical surveys in the basin with companies that were not part of the original proposal, but who are now sufficiently interested as a result of some the Eastern AAPG presentations our group made in Kalamazoo last September. Some of these sites that have been sampled are shown in Figure 3.

\section{REPORT BY TASK}

\section{Task 1 Project Management - J. Wood}

Task Description - Coordinate all aspects of the project between Michigan Technological University (MTU) at Houghton, Michigan, Western Michigan University in Kalamazoo, MI and Cronus Exploration Company LLC in Traverse City, MI. Produce a working document that will outline the project in detail as well as set a schedule of visits and meetings. Coordinate all necessary meetings and will serve as the central repository for all project deliverables and reports. 


\section{Subtask 1.1 Technical Aspects - J. Wood}

\section{Policy - Preparation and Enforcement}

The principal subtasks performed were the preparation of this document, including the master outline and coordinating a geochemical sampling party. Separate subcontracts were negotiated and submitted to Western Michigan University and Cronus Exploration Company LLC by Michigan Technological University.

\section{Travel, Students and Expenditures}

To date eight sampling trips have been made to downstate Michigan to Vernon Field and vicinity. Several trips have also been made to potential project sites. Expenses were paid for Wood and Bornhorst to present papers on the project at the Eastern AAPG meeting this past September.

The project presently supports 1 Masters student, Mr. Chris Seaman. Deyi Xie graduated with a Ph.D. this past summer. He was partially supported on this project.

\section{Subtask 1.2 Financial Reports and Accounting - A. Hein}

\section{Financial documents}

All monthly, quarterly and annual statements and documents have been submitted, including the project Management Plan

C. Asiala has organized a system for keeping copies of all expenditures, bills, invoices and related financial documents that concern this project. The university is keeping track of personnel time and pay for all parties. So far only Michigan Tech is drawing personnel salaries from this project.

\section{Subtask 1.3 Archives - C. Asiala}

\section{Archival of Materials and reports}

Electronic copies of geochemical data have been received from vendors and archived in project databases. These databases have been backed up. Printed versions will be included in reports, including this one.

The Atlas program has been altered to plot the GeoChem Sample locations in bubble plots according to the type of chemical concentration chosen by the user. The GeoChem data can be plotted simultaneously with the well locations or it can be plotted separately. The GeoChem data can also be edited from within the Atlas program. The GeoChem data is stored in 2 tables separate from the well data tables. The first table holds the Permit (unique number assigned to the sample) and its latitude/longitude coordinates. The second table holds the Permit, type of concentration, and concentration value. This allows multiple GeoChem concentration values for each sample.

The Subsurface Visualization Lab Web Site (http://www.geo.mtu.edu/svl) has been updated with reports and figures that pertain to the project. Ongoing updates will be added throughout the project.

\section{Processing of DEM and SDTS files}

In addition to the work in the first Budget Period on Digital Elevation models (DEMs), work has expanded this Budget Period to include gravity data from NOAA on the Central Michigan Basin. This data will be integrated with the rest of the project data and used to help interpret the structural model for the Michigan Basin. 


\section{Task 2 Reservoir Characterization - W. Harrison}

Task Description - Collect, analyze and integrate geologic and engineering data on the Vernon reservoir, particularly structural and stratigraphic data and engineering properties. Determine the reservoir architecture as well as possible prior to drilling the test well. Acquire and interpret 2D seismic line(s). Design, execute and interpret surface geochemical survey(s). Make economic projections and help site wells for development.

\section{Subtask 2.1 Surface Geochemistry - T. Bornhorst}

Work on this task will continue in Budget Period II and will likely be significantly expanded; more samples over more sites. To date over 1500 samples have been collected from 1090 locations.

\section{Subtask 2.2 Reservoir Geology - S. Chittick}

\section{Subsurface data}

We have continued to update and edit subsurface data in our master database files. Presently most of our efforts are going into correcting bad entries and removing duplicate records.

Subtask 2.3 Engineering Parameters- W. Harrison

No activity this period. Work will take up when drilling targets have been selected for the Phase II demonstration wells.

\section{Subtask 2.4 2D Seismic- W. Quinlan}

Acquisition of new seismic data has been deleted from the project task list; instead we will acquire and process existing data.

\section{Task 3 Analysis of Producibility Problem(s) - W. Quinlan}

\section{Subtask 3.1 Drilling - E. Taylor}

No activity this period.

\section{Subtask 3.2 Well Logging - S. Chittick}

No activity this period.

\section{Task 4 Technology Transfer - W. Harrison}

Task Description - Transfer of the technology is recognized as a crucial element in this project. Special efforts will be made to deliver the results in a useable form to our target audience through:

- Meetings and personal contacts.

- Workshops and training courses on use of the data and software

- Electronic distribution of results and data on Internet

- Establishing computer links between Michigan Tech and selected companies

As a result of presentations made on the project results at the Eastern AAPG meeting in Kalamazoo last September, several individuals have expressed interest in ATLAS and we are in the process of transferring the program to them. 


\section{Subtask 4.1 PTTC Workshops - W. Harrison}

\section{Workshops}

A mini-workshop was held in Kalamazoo at the EAAPG meeting in September. J. Wood presented recent developments in the ATLAS program. There were about 30 attendees.

\section{Case histories}

None

\section{Tutorials}

None

\section{Subtask 4.2 Reports - J. Wood}

\section{Publications}

Publish project results in DOE reports and in scholarly journals.

\section{Presentations}

Wood, J. R., 2001 - September EAAPG in Kalamazoo, MI. Presentation of project to date, including last demonstration well and surface geochemistry results.

Wood, J. R., 2001 - September EAAPG in Kalamazoo, MI. Presentation ATLAS software.

Bornhorst, T. J., 2001 - September EAAPG in Kalamazoo, MI. Presentation of project to date, including surface geochemistry results.

Barnes, D., 2001 - September EAAPG in Kalamazoo, MI. Presentation of structural data and interpretation for Vernon Field.

Wood, J. R., 2000 - June SPE Meeting in Long Beach, CA. Presentation of project to date, including surface geochemistry results

Harrison, W. B., 2000 - June DOE Contractors Meeting in Long Beach, CA. Presentation of project to date, including surface geochemistry results

Present results at local and national meeting of geological societies, such as the AAPG.

\section{Subtask 4.3}

\section{WEB Site (formerly Newsletter)}

Publish project results, updates and news in hardcopy and electronic newsletters published by The Subsurface Visualization Lab at Michigan Tech. Place relevant results on Internet in timely fashion. 


\section{FIGURES}




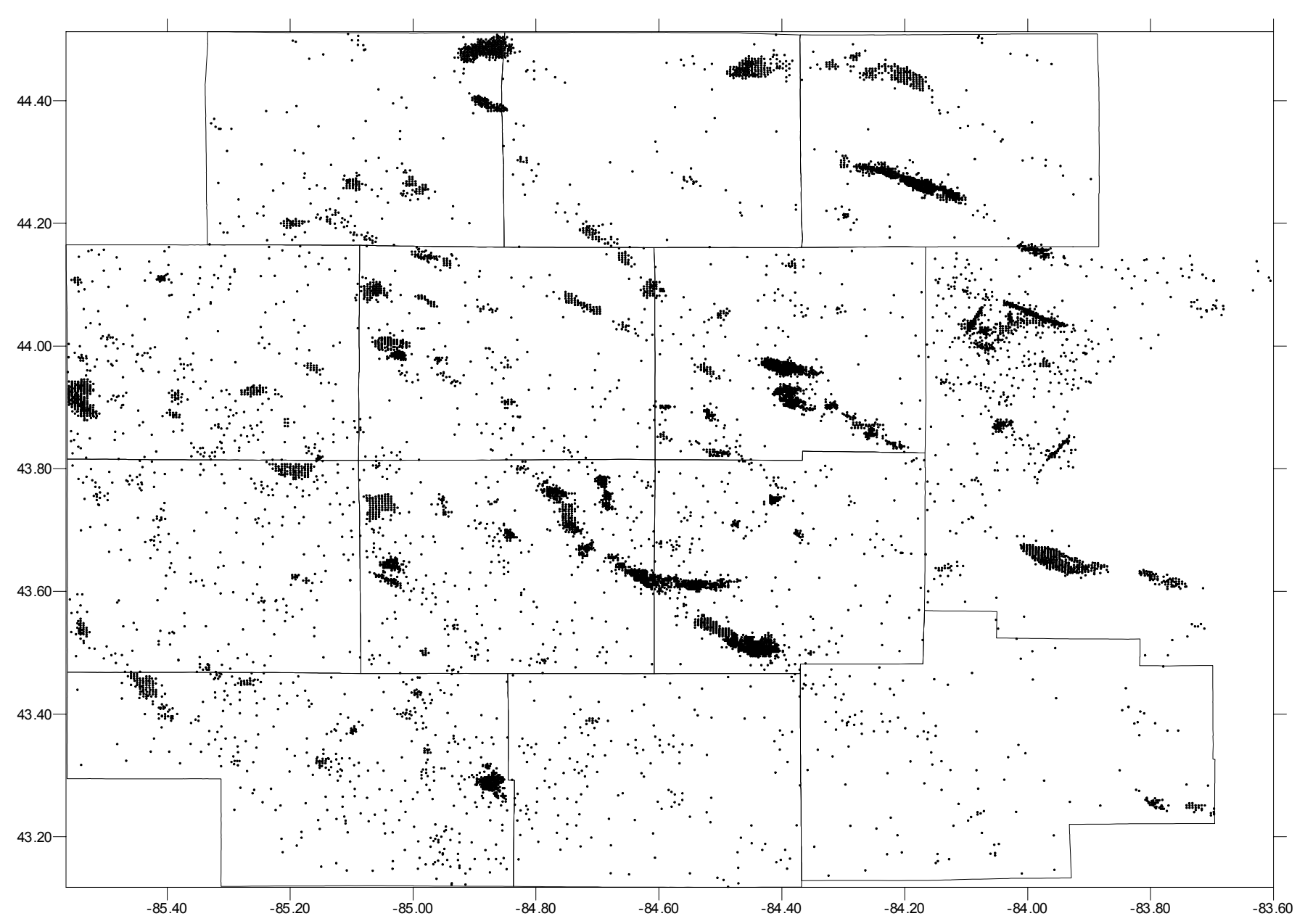

FIGURE 1. Index map showing locations of all wells used in delineating major basin faults in Central Michigan. Lines are county boundaries, circles are wells with Dundee top picks. 


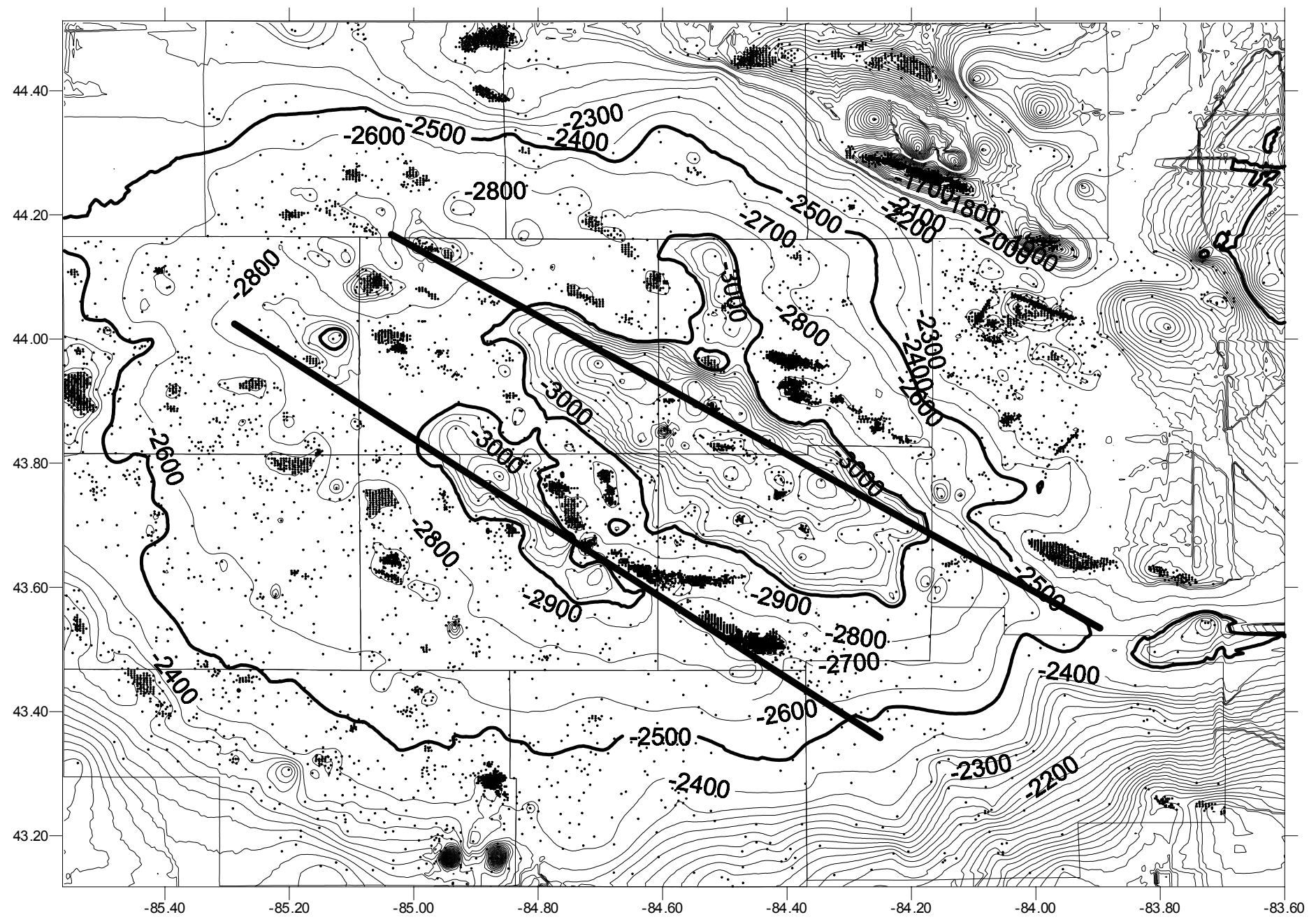

FIGURE 2. Structure contour map on top of the Dundee Formation in the Central Michigan Basin. Faults are shown as heavy lines, light lines are county boundaries, circles are wells with Dundee top picks. Faults are interpreted to exist where contours are heaviest ("stacked"). 


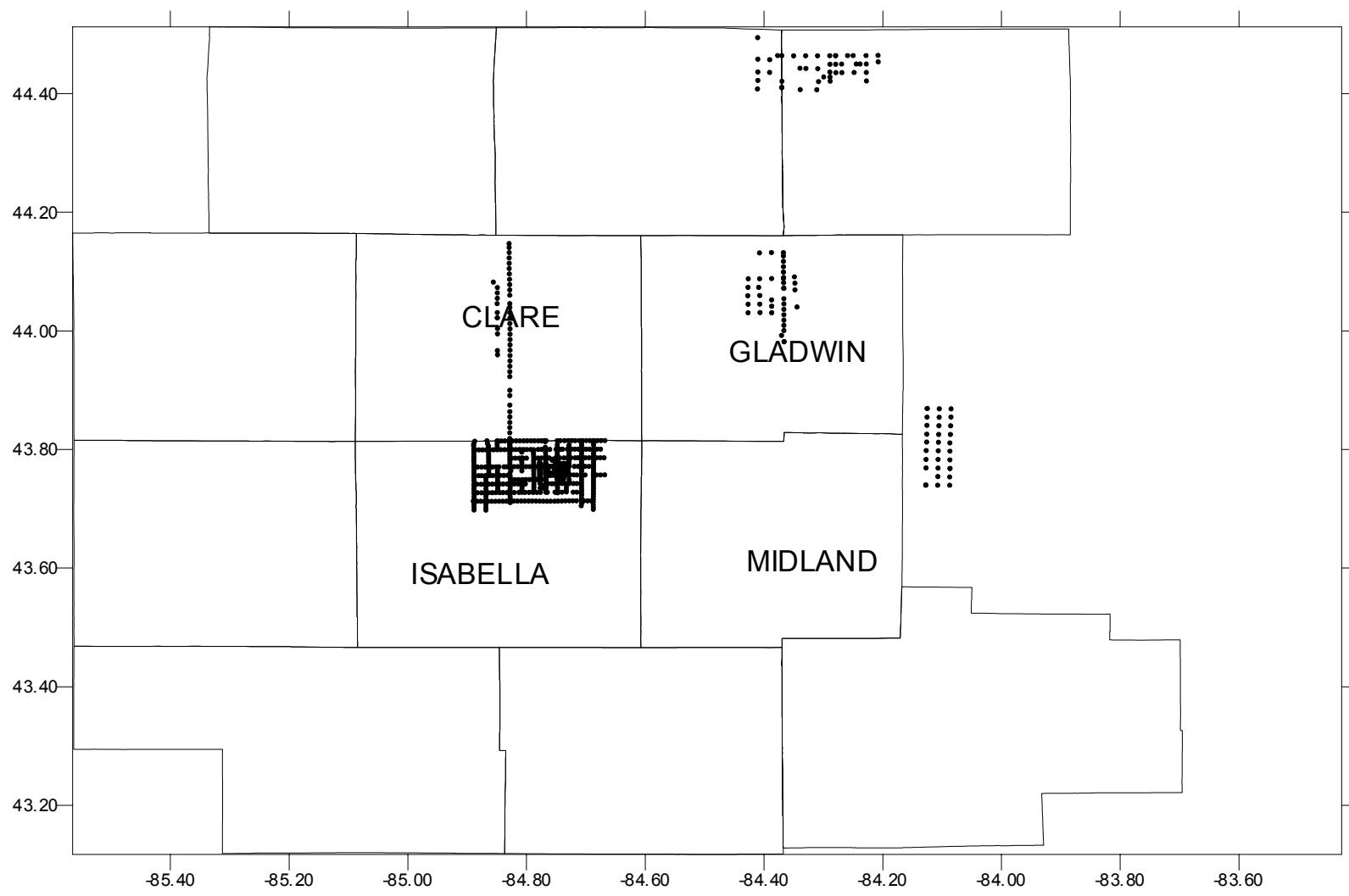

FIGURE 3. Location map for microbial samples in Central Michigan Basin. The high density of points in Isabella County is associated with Vernon Field. Sample locations outside that area are designed to exploit opportunities suggested by discovery of basin center faults. 